Farum

Sociológico

\section{Forum Sociológico}

Série II

$20 \mid 2010$

A pobreza, pluralidade de olhares e de intervenções

\title{
Observar a pobreza em Portugal: uma leitura crítica das principais abordagens à operacionalização do conceito de pobreza
}

\section{Elvira Sofia Leite de Freitas Pereira}

\section{(2) OpenEdition \\ Journals}

Edição electrónica

URL: https://journals.openedition.org/sociologico/182

DOI: 10.4000/sociologico.182

ISSN: 2182-7427

Editora

CICS.NOVA - Centro Interdisciplinar de Ciências Sociais da Universidade Nova de Lisboa

\section{Edição impressa}

Data de publição: 1 junho 2010

Paginação: $57-66$

ISSN: 0872-8380

\section{Refêrencia eletrónica}

Elvira Sofia Leite de Freitas Pereira, «Observar a pobreza em Portugal: uma leitura crítica das principais abordagens à operacionalização do conceito de pobreza», Forum Sociológico [Online], 20 | 2010, posto online no dia 05 setembro 2012, consultado o 29 março 2022. URL: http:// journals.openedition.org/sociologico/182 ; DOl: https://doi.org/10.4000/sociologico.182

Este documento foi criado de forma automática no dia 29 março 2022.

(C) CICS.NOVA 


\title{
Observar a pobreza em Portugal: uma leitura crítica das principais abordagens à operacionalização do conceito de pobreza
}

\author{
Elvira Sofia Leite de Freitas Pereira
}

\section{Introdução}

1 De acordo com a definição oficialmente adoptada pelo Conselho das Comunidades Europeias em 1975: pessoas em situação de pobreza são indivíduos ou famílias cujos recursos são de tal forma baixos que os excluem do modo de vida mínimo aceitável no Estado-Membro em que vivem (75/458/EEC, Decisão do Conselho de 22 de Julho de 1975).

2 Apesar de a noção de pobreza aceite a nível europeu estar associada, desde aquela data, à noção de nível de vida mínimo aceitável num determinado Estado-Membro, o principal indicador "oficial", seleccionado no seio da União Europeia (UE), para a observação e a avaliação da pobreza é uma medida monetária relativa, que identifica como pobres os indivíduos com rendimento inferior a $60 \%$ do rendimento equivalente mediano no Estado-Membro em que vivem - o designado limiar relativo de pobreza. A existência de um indicador "oficial" a nível europeu, associada às complexidades e ambiguidades do conceito de pobreza e às dificuldades metodológicas na sua operacionalização, levou à sua adopção generalizada nos estudos de medição da pobreza, nomeadamente em Portugal.

3 Esta utilização de medidas monetárias relativas para observar e avaliar a pobreza foi, desde cedo, expressivamente criticada no seio da comunidade científica. Um dos principais problemas que este tipo de medida coloca é o da reorientação do objecto de observação da pobreza para os rendimentos "relativamente" baixos, divorciando desta forma a avaliação da pobreza da sua definição operacional e da sua expressão 
fundamental como "dano grave ou obstáculo a uma bem-sucedida participação social" Do lado das ciências sociais, abandona-se assim o objectivo de identificação das necessidades que todos os indivíduos deveriam poder satisfazer (o nível de vida mínimo aceitável), bem como dos seus mecanismos de satisfação e dos bens económicos ou do nível de rendimento que permitem satisfazê-las na sociedade onde se observa a pobreza. Do lado da audiência extra-académica, a pobreza, vista como uma situação de rendimentos relativamente baixos, perde o lugar de destaque que mereceria enquanto problema social grave que impõe à sociedade um dever de resposta.

4 Ao nível da UE, o reconhecimento da inadequação daquele indicador "oficial" para observar e avaliar a pobreza, que se tornou sobretudo visível com a adesão de novos países, nomeadamente do Leste Europeu, levou ao desenvolvimento e à adopção de outros indicadores, utilizados como complementares do indicador monetário dominante, e à procura de formas alternativas de medição da pobreza, de que é exemplo o estudo de Bradshaw e Mayhew (2011), encomendado pela Comissão Europeia.

5 Em Portugal, o descontentamento com o limiar referido é espelhado quer na Resolução da Assembleia da República n. ${ }^{\circ}$ 31/2008, que recomenda "a definição de um limiar de pobreza em função do nível de rendimento nacional e das condições de vida padrão na nossa sociedade" para servir de "referência à definição e à avaliação das políticas públicas de erradicação da pobreza", quer no desenvolvimento no meio académico de propostas de operacionalização do limiar de pobreza alternativas à dominante (Pereira, 2010).

6 No contexto actual, o desenvolvimento de uma medida objectiva, consensual, adequada para a observação da pobreza em Portugal, apoiada em investigação científica, e que permita determinar o rendimento necessário para obter o nível de vida mínimo aceitável no nosso país é um desafio importante que se coloca à investigação social nesta área. É neste contexto que a reflexão apresentada neste artigo é realizada.

7 o principal objectivo deste artigo é o de apresentar uma leitura crítica das principais abordagens à operacionalização do conceito de pobreza, apoiada em resultados de investigação recente, utilizando como guião de leitura das mesmas o quadro teórico e normativo da abordagem das capacidades proposta por Amartya Sen². Esta leitura crítica enquadrará quer as principais abordagens à operacionalização do conceito de pobreza na investigação científica em Portugal, quer as principais medidas actualmente utilizadas para observar a pobreza em Portugal, e terminará com algumas considerações finais, salientando alguns aspectos que poderão servir de guia à investigação social em Portugal na resposta ao desafio colocado.

\section{Abordagens à operacionalização do conceito de pobreza: uma leitura crítica}

8 Da extensa literatura produzida sobre pobreza resulta um consenso relativamente alargado de que a pobreza pode ser identificada como uma situação em que não são satisfeitas determinadas necessidades, ou em que não é realizado um nível de vida mínimo aceitável, por carência de recursos económicos, existindo sempre um elemento de privação material involuntária (Quadro 1). 
Quadro 1 Conceitos de pobreza associados a diferentes abordagens

\begin{tabular}{|c|c|}
\hline $\begin{array}{l}\text { Abordagem } \\
\text { baseada } \\
\text { na } \\
\text { subsistência }\end{array}$ & $\begin{array}{l}\text { "Famílias cujos rendimentos totais são insuficientes para obter o mínimo } \\
\text { necessário para a manutenção da mera eficiência física." (Rowntree, 1902: 86) }\end{array}$ \\
\hline $\begin{array}{l}\text { Abordagem } \\
\text { baseada } \\
\text { na privação } \\
\text { relativa }\end{array}$ & $\begin{array}{l}\text { "Pode dizer-se que indivíduos, famílias e grupos da população se encontram em } \\
\text { pobreza quando não têm recursos para obter os tipos de dieta, participar nas } \\
\text { actividades e ter as condições de vida e comodidades que são comuns, ou pelo } \\
\text { menos largamente encorajadas ou aprovadas, nas sociedades a que } \\
\text { pertencem. Os seus recursos estão tão seriamente abaixo dos controlados pelo } \\
\text { indivíduo ou família médios que eles são de facto excluídos dos padrões de vida, } \\
\text { costumes e actividades correntes." (Townsend, 1979: } 31 \text { ) }\end{array}$ \\
\hline $\begin{array}{l}\text { Abordagem } \\
\text { baseada } \\
\text { nas } \\
\text { capacidades }\end{array}$ & $\begin{array}{l}\text { “A pobreza deve ser vista como privação de capacidades básicas (...) ainda que a } \\
\text { pobreza seja também inter alia uma questão de inadequação de meios económicos } \\
\text { da pessoa (os meios para evitar a privação de capacidade)." (Sen, 1992: 109-111) }\end{array}$ \\
\hline $\begin{array}{l}\text { Abordagem } \\
\text { baseada } \\
\text { na percepção } \\
\text { social } \\
\text { de } \\
\text { necessidades }\end{array}$ & $\begin{array}{l}\text { “Este estudo define 'pobreza' em termos de uma insatisfação forçada de } \\
\text { necessidades socialmente percebidas.” (Mack e Lansley, 1985: 39) } \\
\text { "Como Mack e Lansley, procuramos identificar aqueles que (por causa da falta de } \\
\text { recursos) não conseguem obter os que são vistos como os padrões mínimos na } \\
\text { sociedade, como evidenciado pela insatisfação forçada de necessidades definidas } \\
\text { socialmente." (Nolan e Whelan, 1996: } \\
\text { 73-74) }\end{array}$ \\
\hline
\end{tabular}

9 O consenso, contudo, termina naquela definição muito lata e os estudos distinguem-se de forma fundamental na especificação que realizam das duas dimensões fundamentais - recursos e necessidades - e nas variáveis e procedimentos metodológicos utilizados para identificar os pobres.

De um modo geral, é possível distinguir três linhas principais de diferenciação em termos das opções prosseguidas nos estudos na conceptualização da pobreza e na identificação dos pobres: a) a dimensão de observação, b) o padrão de referência, e c) o grau de integração das percepções sociais e individuais. Nesta secção, após uma breve apresentação do quadro teórico e normativo da abordagem das capacidades, desenvolvida por Amartya Sen, será realizada uma leitura destas três linhas de diferenciação guiada por esse quadro teórico e normativo.

\section{0 quadro teórico e normativo da abordagem das capacidades}

11 Sen (1999 [1981], 1983, 1992) considera a existência de seis espaços diferentes na avaliação e conceptualização da pobreza e do padrão de vida: (1) o espaço do rendimento ou recursos, (2) o espaço dos bens, ${ }^{3} \mathrm{o}$ espaço das características dos bens, ${ }^{4} \mathrm{O}$ espaço da capacidade para realizar funcionamentos [capability to function], ${ }^{5} \mathrm{o}$ espaço dos 
funcionamentos [functionings], e (6) o espaço das utilidades. Estes diferentes espaços estão relacionados de acordo com a seguinte sequência: o rendimento permite obter bens, os bens possuem determinadas características, estas características conferem aos indivíduos, dados os seus factores de conversão, uma determinada capacidade, a escolha associada ao exercício dessa capacidade traduz-se na realização de funcionamentos e a realização desses funcionamentos origina um determinado nível de utilidade (Figura 1).

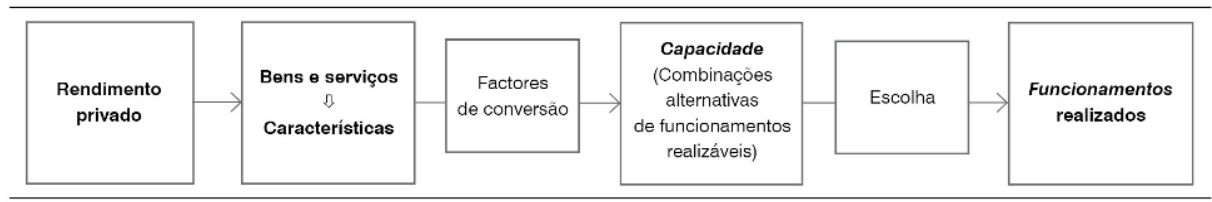

Figura 1 Os principais espaços de avaliação e conceptualização da pobreza na abordagem das capacidades (Adaptado de Robeyns, 2005: 98)

Para Amartya Sen, tanto a capacidade para realizar funcionamentos como os funcionamentos têm valor intrínseco: a capacidade indica o que uma pessoa pode realizar e os funcionamentos o que a pessoa realiza. A capacidade de uma pessoa consiste assim "nas combinações alternativas de funcionamentos cuja realização é factível para ela" e os funcionamentos reflectem "as várias coisas que uma pessoa pode considerar valioso fazer ou ter" (Sen, 2000 [1999]: 95). Os funcionamentos valorizados podem corresponder a realizações (necessidades) elementares, "como ser adequadamente nutrido e livre de doenças evitáveis", ou a realizações (necessidades) mais complexas, "como poder participar da vida da comunidade e ter respeito próprio" (idem: 95).

13 Ao identificar como objectos de valor a capacidade para realizar funcionamentos e os funcionamentos, a abordagem das capacidades fornece um enquadramento normativo para a conceptualização e a avaliação da pobreza e do padrão de vida.

14 A rejeição da utilidade, definida em termos de uma característica mental como prazer, felicidade, satisfação ou desejo, como base informacional adequada para avaliar a pobreza e o padrão de vida é justificada pelo facto de a mesma ser, por um lado, demasiado desligada da natureza da vida que as pessoas levam e, por outro, "maleável de mais para constituir-se um guia confiável para a privação e a desvantagem" (Sen, 2000 [1999]: 82).

15 A rejeição do rendimento, dos bens e das características dos bens como base informacional adequada para avaliar a pobreza e o padrão de vida é sustentada na grande heterogeneidade dos seres humanos (Sen, 1992; 2000 [1999]). A grande heterogeneidade dos seres humanos, expressa em características individuais e em circunstâncias externas, implica a existência de diferenças substanciais na conversão do rendimento e recursos pessoais em funcionamentos ou em satisfação de necessidades (Sen, 1992; 2000 [1999]). Sen (2000 [1999]) identifica cinco fontes distintas de variação na relação entre meios (rendimento, bens e características dos bens) e fins a atingir (capacidade e funcionamentos): (i) variações nas características individuais, (ii) variações nas condições ambientais, (iii) variações no acesso a bens de consumo colectivo e a bens de consumo individual fornecidos pelo Estado, (iv) variações intersociais nos bens necessários para realizar funcionamentos fundamentais e (v) variações na distribuição intrafamiliar dos meios.

Embora, tanto a capacidade para realizar funcionamentos como os funcionamentos tenham valor intrínseco, Sen defende que, para muitas finalidades avaliatórias, e em particular 
para a avaliação do padrão de vida e da pobreza, o enfoque correcto é o espaço da capacidade para realizar funcionamentos - ou seja, as oportunidades reais ou as liberdades substantivas para fazer e ser aquilo que a pessoa racionalmente valoriza (Sen, 2000 [1999]) - e não o da realização dessa capacidade, que resulta, em última análise, de uma escolha.

No entanto, a avaliação da capacidade individual pode ser extremamente difícil, uma vez que aquilo que observamos são as escolhas e as realizações dos indivíduos e não as potenciais combinações alternativas de funcionamentos cuja realização é possível para os mesmos (Sen, 1992). Nesse sentido, uma avaliação centrada no rendimento, como forma de apreender a capacidade individual para realizar os funcionamentos relevantes, desde que as variações sistemáticas na relação entre rendimento e capacidade sejam consideradas e a determinação do nível de rendimento suficiente seja realizada por referência a um determinado nível mínimo aceitável de capacidade para realizar funcionamentos, tem mérito próprio (Sen, 1999 [1981]; 1992) 3 .

\section{A dimensão de observação da pobreza: análise indirecta ou análise directa?}

18 Como mencionado anteriormente, a maior parte dos estudos realizados na área da pobreza assumem explícita ou implicitamente duas dimensões - recursos e necessidades - na conceptualização da pobreza. Na maior parte dos casos, no entanto, para a identificação dos pobres os estudos privilegiam uma das dimensões ou, na terminologia de Amartya Sen, um determinado espaço para identificar os pobres.

19 Assim, alguns estudos observam os recursos dos indivíduos, identificando como pobres aqueles que têm recursos (ou rendimentos) insuficientes, relativamente a um padrão definido - o que é vulgarmente designado de análise indirecta. Outros estudos observam as condições de vida, identificando como pobres os indivíduos que sofrem de privação (forçada por insuficiência de recursos) nas condições de vida, relativamente a um padrão definido - o que normalmente se designa de análise directa.

20 A análise indirecta tem dominado a medição da pobreza em Portugal e as questões metodológicas de identificação dos pobres associadas a este tipo de abordagem foram objecto de reflexões bastante aprofundadas em diversas teses de doutoramento (e. g. Bruto da Costa, 1992; Ferreira, 2000; Nunes, 2004; Pereira, 2010; Pereirinha, 1988; Rodrigues, 2007).

21 Teoricamente, se, por um lado, fosse possível determinar com grande precisão o nível de recursos de que os agregados/indivíduos necessitam para obter um padrão de vida mínimo aceite, bem como o nível de recursos disponível dos agregados/indivíduos, e, por outro, fosse possível determinar com grande precisão as situações de privação material forçada por falta de recursos relativamente a um padrão de vida mínimo aceite, seria de esperar uma grande consistência na identificação dos pobres, entre as abordagens indirecta e directa.

22 Na prática, nas duas últimas décadas tem sido empiricamente verificado que existem diferenças substanciais nos resultados, em termos de níveis de pobreza e de identificação dos pobres, entre a abordagem directa, baseada em indicadores de privação, e a abordagem indirecta, que é normalmente baseada no rendimento disponível. Em Portugal, por exemplo, Pereira (2010) observou uma discordância na 
identificação dos indivíduos em situação de pobreza de $22 \%$, ou seja, $22 \%$ dos indivíduos eram identificados como pobres apenas numa das medidas (pobres inconsistentes).

Esta falta de consistência das medidas não é marginal nem específica de alguns países e, como refere Perry (2002), não pode ser ignorada. De facto, se ambas as medidas correspondem a operacionalizações do mesmo conceito, o conceito de pobreza, a falta de consistência entre ambas levanta questões importantes de fiabilidade e validade das medidas normalmente utilizadas para identificar os pobres (Bradshaw e Finch, 2003). Vários estudos têm demonstrado que a inconsistência observada é explicada por factores relacionados com as "dificuldades em medir os conceitos teóricos envolvidos" (Layte et al., 2001: 428), em parte ilustradas pelo quadro analítico da abordagem das capacidades.

Colocam-se assim desafios importantes aos investigadores na área da pobreza no sentido de melhorar a operacionalização quer das medidas baseadas no rendimento quer das medidas baseadas na privação. Por outro lado, tendo em conta que ambos os tipos de medidas traduzem aspectos relevantes da situação e da vulnerabilidade à situação de pobreza (Pereira, 2010), a combinação de ambas as medidas na análise da pobreza pode contribuir tanto para uma melhor identificação das situações de pobreza como para uma melhor compreensão dos factores e dos processos que contribuem para a privação material forçada por insuficiência de recursos.

\section{O padrão de referência para identificar os pobres: absoluto ou relativo?}

Relativamente ao padrão de referência para identificar os pobres, é importante considerar pelo menos dois níveis distintos do debate sobre a avaliação da pobreza tal como propõem Chiappero-Martinetti e Moroni (2007). O primeiro nível de debate está associado à questão: $O$ que determina uma situação de pobreza? O segundo nível de debate está associado à questão: É possível identificar uma lista completa e fixa de necessidades ou funcionamentos relevantes a partir da qual possa ser determinada a situação de pobreza independentemente dos contextos sociais, culturais e históricos?

Os estudos que adoptam uma abordagem relativa pura à determinação da situação de pobreza identificam como estando em situação de pobreza todos os indivíduos que, por exemplo, no caso de a medição ser indirecta, estão abaixo de um determinado nível de rendimento definido por referência à distribuição do rendimento observada na sociedade em que se inserem, de que é exemplo o indicador monetário relativo adoptado na UE, ou que, no caso de a medição ser directa, não possuem os bens nem desenvolvem as actividades que a maior parte dos indivíduos possuem ou desenvolvem na sociedade em que se inserem, principal critério utilizado por Townsend (1979) na selecção de indicadores para o desenvolvimento de uma medida de privação relativa. Ou seja, o padrão de referência para aferir a situação de pobreza corresponde ao padrão de vida médio, corrente ou comum.

Em Portugal, a abordagem relativa é no presente claramente dominante na medição da pobreza, quer nos estudos oficiais quer na investigação científica, reflectindo uma tendência de uniformização de critérios na medição indirecta da pobreza, observada sobretudo nos estudos realizados nos últimos 10 anos. Esta uniformização, associada à adopção generalizada do indicador "oficial" estabelecido ao nível da UE, nalguns casos justificada por razões práticas de harmonização e comparabilidade, não reflecte 
contudo qualquer consenso científico relativamente à adequação do mesmo para observar e medir a pobreza em Portugal ${ }^{4}$.

Ora, a utilização de um indicador monetário relativo encerra um problema fundamental para a observação da pobreza: o estabelecimento do limiar é totalmente desligado das condições de vida que podem ser obtidas com o rendimento aí implícito. Nesse sentido, a utilização de um limiar relativo está intimamente ligada a uma noção de pobreza enquanto situação de rendimentos relativamente baixos e não enquanto situação de rendimentos inadequados para obter um determinado padrão de vida aceite como adequado - qualquer relação entre o rendimento "necessário" implícito no limiar para escapar à pobreza e o rendimento necessário para realizar funcionamentos relevantes é pura coincidência. o limiar assim obtido pode estar quer abaixo daquilo que é necessário para realizar os funcionamentos relevantes, quer acima.

o Gráfico 1 ilustra as diferenças no padrão de vida implícitas num limiar relativo assente num quadro de referência nacional.

Gráfico 1 Limiares relativos de pobreza ( $60 \%$ do rendimento mediano equivalente do respectivo país) em 2009

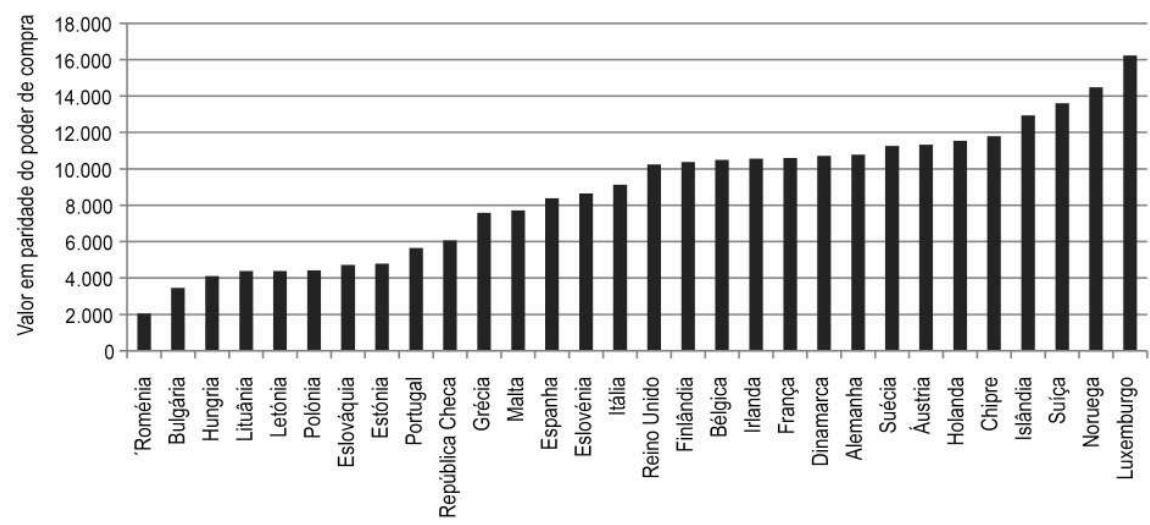

FONTE: Eurostat, 2011

Não é assim surpreendente que ao nível europeu, onde, por um lado, na determinação da taxa de risco de pobreza (análise indirecta) o padrão de referência para o estabelecimento do limiar de pobreza é nacional - $60 \%$ do rendimento mediano equivalente do Estado-Membro respectivo - e, por outro, na determinação da taxa de privação material (análise directa), assente numa lista comum de nove indicadores de privação, o padrão de referência para o estabelecimento do limiar é único e comum aos diferentes países (três privações ou mais), se verifiquem importantes discrepâncias no nível estimado de pobreza/privação por cada uma destas medidas (Gráfico 2)5.

De facto, existem diversos países com taxas de privação material bastante inferiores às taxas de risco de pobreza, identificados do lado esquerdo do Gráfico 2, e diversos países com taxas de privação material muito superiores às taxas de risco de pobreza medida pelo rendimento, cujos casos mais extremos estão identificados do lado direito do Gráfico 2. A situação de Portugal relativamente à da Espanha e à da Hungria é, a este propósito, ilustrativa. Embora Espanha apresente uma taxa de risco de pobreza próxima (e até ligeiramente superior) à observada em Portugal (respectivamente 19,5\% e 17,9\%), a taxa de privação material observada em Espanha corresponde a quase metade da observada em Portugal (respectivamente 11,3\% e 21,5\%). Por outro lado, na 
Hungria, onde se observa uma taxa de risco de pobreza significativamente inferior à observada em Portugal (respectivamente $12,4 \%$ e 17,9\%), a taxa de privação material corresponde a praticamente o dobro da observada em Portugal (respectivamente 40,9\% e $21,5 \%)$.

Gráfico 2 Taxa de risco de pobreza e taxa de privação material, em países europeus, em 2009

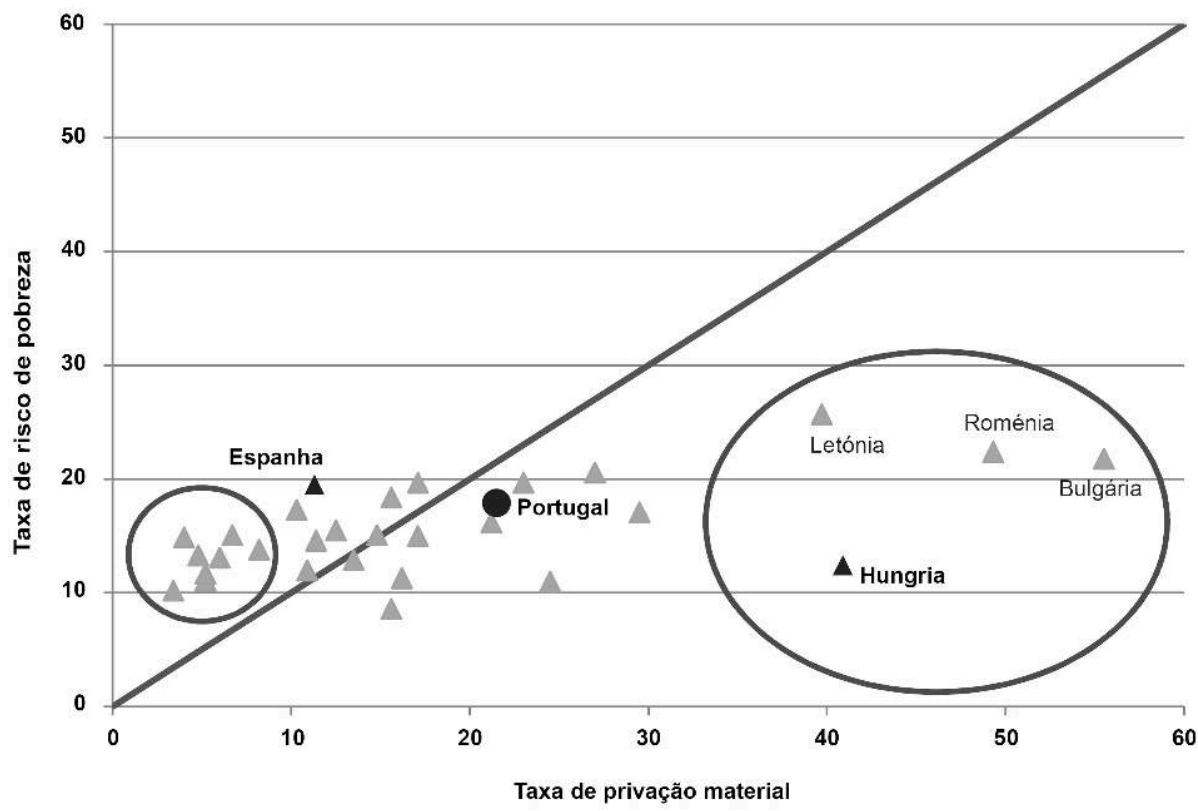

FONTE: Eurostat, 2011

Neste contexto, importa referir a discussão que vem emergindo na literatura sobre medição da pobreza na UE relativamente à eventual necessidade de adoptar medidas de pobreza assentes num padrão de referência europeu, em parte associada à eventual europeização dos grupos de referência e suas implicações na medição da pobreza (e. g., Goedemé e Rottiers, 2011; Kangas e Ritakallio, 2007; Whelan e Maître, 2009).

Nos estudos que adoptam uma abordagem absoluta à determinação da situação de pobreza, considera-se que aquilo que determina uma situação de pobreza é, na terminologia da abordagem das capacidades, a incapacidade material para realizar determinados funcionamentos fundamentais: “a pobreza não é só um assunto de ser relativamente mais pobre do que os outros na sociedade, mas sim o de não ter algumas oportunidades básicas de bem-estar material" (Sen, 1985: 669).

De acordo com esta abordagem, a posição relativa do indivíduo por referência a um padrão médio ou comum (nos espaços do rendimento ou dos bens e actividades) é um guia pobre da (in)capacidade para realizar funcionamentos fundamentais. Além disso, considera-se a existência de um núcleo de capacidades materiais básicas, associadas à noção de necessidades básicas universais, sobre as quais é possível reunir um consenso alargado de urgência de satisfação independentemente do quadro societal. Esta urgência está, na terminologia de Doyal e Gough (1991), associada à ideia de evitar um 
dano grave [serious harm], que pode ser equacionado como um obstáculo a uma bemsucedida participação social.

Quer a abordagem das capacidades quer a abordagem das necessidades reconhecem a existência de variações substanciais interindividuais e intersociais nos recursos e nos bens necessários para obter as mesmas capacidades ou satisfazer as mesmas necessidades. o quadro analítico da abordagem das capacidades salienta, aliás, diferentes fontes de variação na relação entre meios e fins. $\mathrm{Na}$ abordagem das necessidades, este reconhecimento assenta na diferenciação entre bens económicos, meios de satisfação das necessidades [satisfiers] e necessidades (Doyal e Gough, 1991; Max-Neef, 1992).

Neste sentido, uma privação absoluta no espaço das capacidades, ou da satisfação de necessidades, está relacionada com uma privação relativa no espaço dos bens e recursos: "Se virmos o problema de conceptualização da pobreza a esta luz, não há conflito entre um elemento absolutista irredutível na noção de pobreza (relacionado com as capacidades e o nível de vida) e uma 'completa relatividade', a que Peter Townsend se refere, se esta última for interpretada como aplicando-se aos bens e recursos" (Sen, 1983: 161).

Assim, aquilo que distingue a abordagem absoluta à determinação da situação de pobreza da abordagem relativa não é a utilização pela primeira de um mesmo cabaz de bens ou de um mesmo limiar de rendimento para aferir a satisfação de necessidades independentemente dos contextos específicos. Aquilo que distingue a abordagem absoluta é o facto de esta partir da definição de funcionamentos fundamentais ou necessidades básicas para a determinação do nível de recursos ou dos bens necessários para evitar a pobreza - que é aquele que permite realizar esses funcionamentos ou satisfazer essas necessidades. Esta abordagem está assim mais próxima da definição mais consensual de pobreza.

No sentido aqui atribuído, uma abordagem absoluta à operacionalização do conceito de pobreza foi prosseguida, por exemplo, naquele que é considerado o primeiro estudo científico sobre pobreza de Rowntree (1902), realizado no Reino Unido, no primeiro estudo compreensivo sobre pobreza em Portugal de Bruto da Costa et al. (1985) e, mais recentemente, por Pereira (2010). Estes três estudos têm em comum a determinação de um limiar de pobreza, ao nível do rendimento, por referência ao rendimento necessário para obter um determinado padrão de vida mínimo aceite. Refira-se que no estudo de Pereira (2010) o limiar assim estabelecido correspondia a cerca de $75 \%$ do valor mediano do rendimento disponível por adulto equivalente, sendo por isso superior ao limiar implícito no indicador oficial de pobreza utilizado em Portugal.

Relativamente ao segundo nível de debate sobre o padrão de referência, ou seja, sobre a possibilidade de identificação de uma lista completa e fixa de capacidades materiais relevantes a partir da qual possa ser determinada a situação de pobreza independentemente dos contextos sociais, culturais e históricos, a resposta de Amartya Sen é claramente negativa, e a este nível o autor adopta uma perspectiva que se pode considerar relativa. Como refere Sen (2000 [1999]): "Pode haver debates substanciais sobre que funcionamentos específicos devem ser incluídos na lista de realizações importantes e as capacidades correspondentes. Essa questão valorativa é inescapável em um exercício avaliatório desse tipo, e um dos principais méritos da abordagem é a necessidade de tratar essas questões de julgamento de um modo explícito, em vez de escondê-las em alguma estrutura implícita" (p. 95). 
40 De acordo com Sen (2000 [1999]), existem algumas capacidades básicas que serão relevantes na maioria das análises, como, por exemplo, a capacidade para ser adequadamente nutrido, a capacidade para evitar a morbilidade, a capacidade para participar da vida da comunidade. Estas capacidades básicas aproximam-se assim da noção de necessidades básicas universais. Mas, como refere Gough (2002), o conhecimento codificado das ciências sociais e humanas sobre as necessidades muda e expande-se com o tempo, pelo que o conceito de necessidade humana tem de estar "historicamente aberto a essas melhorias contínuas na compreensão" (p. 10).

41 Por outro lado, Sen (2000 [1999]) argumenta que a teoria pura não pode fornecer uma lista completa e fixa de capacidades básicas ou funcionamentos relevantes aplicável a todas as sociedades. Para este autor, a lista das realizações importantes bem como a importância relativa das diferentes capacidades nela incluída não podem estar divorciadas da cultura e das realidades sociais (idem). A sua identificação exige participação e discussão pública - "é um exercício de 'escolha social', e requer discussão pública e entendimento e aceitação democráticos" (idem: 99). Uma das vantagens de uma abordagem centrada em funcionamentos fundamentais é a de que é possível obter um acordo mais alargado sobre a sua importância do que sobre a importância de determinados bens ou formas particulares de realizar esses funcionamentos (Sen, 1992).

\section{A integração das percepções sociais e individuais na identificação dos pobres}

O grau de integração das percepções sociais e individuais na operacionalização do conceito de pobreza é uma outra linha importante de diferenciação. Num primeiro plano, é possível distinguir a abordagem objectiva da abordagem subjectiva. No primeiro caso, abordagem objectiva, a medida desenvolvida permite avaliar a situação de pobreza de cada indivíduo relativamente a um determinado padrão comum definido, sendo o seu resultado independente da apreciação subjectiva do próprio indivíduo relativamente à sua situação (de pobreza ou não pobreza). No segundo caso, abordagem subjectiva, é a apreciação subjectiva do próprio indivíduo relativamente à sua situação o único critério utilizado para a sua identificação como pobre ou não pobre.

43 A operacionalização de uma medida objectiva do conceito de pobreza pode envolver uma combinação de julgamento do investigador, referências científicas e observação empírica dos padrões ou das percepções sociais prevalecentes. Contudo, Sen (2000 [1999]) defende que numa "avaliação-padrão" [standard-evaluation], com o objectivo de identificar as situações de pobreza, o padrão deve reflectir os valores partilhados numa determinada sociedade sobre os funcionamentos fundamentais. Dito de outro modo, para Sen (1999 [1981]), "um diagnóstico objectivo das 'condições de privação' exige uma compreensão objectiva dos 'sentimentos de privação"' (p. 33)6.

O estudo de Mack e Lansley (1985), que representa uma abordagem à operacionalização do conceito de pobreza que ficou conhecida por abordagem consensual, representa precisamente uma aproximação ao diagnóstico objectivo das condições baseado numa compreensão objectiva dos sentimentos de privação. De facto, os autores procuraram definir o padrão de vida mínimo, a partir do qual é aferida a situação de pobreza dos indivíduos, com base na percepção social prevalecente (maioritária) sobre os bens, serviços e actividades que todos deveriam poder ter e ninguém deveria ter de viver 
$\mathrm{sem}^{7}$. De acordo com os autores, esta abordagem "afasta o conceito de pobreza de um exercício arbitrário de julgamento pelos «especialistas», políticos e governos... e abre-o a uma representação mais democrática de interesses" (Mack e Lansley, 1985: 47).

Em Portugal, são praticamente inexistentes os estudos que utilizam uma abordagem consensual na operacionalização do conceito de pobreza. Uma excepção é o estudo de Pereira (2010), que, partindo de uma definição operacional de pobreza enquanto situação de recursos económicos insuficientes para obter o padrão de vida mínimo aceite ou largamente aprovado como tal em Portugal, combina duas opções diferenciadas na determinação desse padrão de vida mínimo - uma que resulta do reconhecimento da existência de um núcleo irredutível de privação absoluta e outra que resulta do objectivo de integrar a percepção social prevalecente na medida de pobreza. Assim, a primeira opção prosseguida envolve o recurso ao conhecimento codificado - referências científicas - para definir as capacidades materiais, relacionadas com realizações elementares associadas à saúde física, relativamente às quais este conhecimento codificado dá uma resposta satisfatória. Na identificação de outras capacidades materiais, nomeadamente as associadas a realizações mais complexas, a opção prosseguida nesse estudo envolve o recurso aos dados do Eurobarómetro Especial n. $\mathrm{o}$ 279, sobre Pobreza e Exclusão $(\mathrm{EC}, 2007)^{8}$. Este Eurobarómetro permite identificar os itens que corporizam, de acordo com a abordagem consensual, o padrão de vida mínimo aceite enquanto tal na sociedade portuguesa (itens que a maioria dos indivíduos em Portugal considera "Absolutamente necessário, ninguém deveria ser privado") $)^{9}$

Neste contexto, importa verificar se os indicadores de privação seleccionados para o desenvolvimento da mais recente medida oficial de privação material ao nível da UE passam o "teste do consenso" em Portugal, ou seja, se são percebidos pela maioria em Portugal como absolutamente necessários ${ }^{10}$.

No Quadro 2 são apresentados os dados relativos quer à percepção do item como absolutamente necessário em Portugal quer à privação material forçada, em cada item, observada em Portugal. Dos nove itens seleccionados, apenas quatro eram considerados em 2007 como absolutamente necessários por uma maioria da população em Portugal, embora todos fossem considerados pela maioria como necessários (absolutamente necessário ou necessário) (EC, 2007). Um dos itens seleccionados - a capacidade para pagar uma semana de férias, por ano, fora de casa - não corresponde sequer a um padrão comum em Portugal, dado que a maioria dos indivíduos em Portugal $(63,3 \%)$ se encontrava em situação de privação relativamente a este item.

Quadro 2 Indicadores seleccionados, ao nível europeu, para observar a privação material

\begin{tabular}{|l|l|l|}
\hline & $\begin{array}{l}\text { Absolutamente } \\
\text { necessário } \\
\text { em Portugal } \\
\text { (\% da } \\
\text { população)** }\end{array}$ & $\begin{array}{l}\text { Privação } \\
\text { forçada } \\
\text { em Portugal } \\
(\% \text { da } \\
\text { população)*** }\end{array}$ \\
\hline $\begin{array}{l}\text { 1. Capacidade para assegurar o pagamento imediato, sem } \\
\text { recorrer a empréstimo, de uma despesa inesperada próxima } \\
\text { do valor mensal da linha de pobreza }\end{array}$ & 45 & 27,8 \\
\hline
\end{tabular}




\begin{tabular}{|c|c|c|}
\hline $\begin{array}{l}\text { 2. Capacidade para pagar uma semana de férias, por ano, fora } \\
\text { de casa, suportando a despesa de alojamento e viagem para } \\
\text { todos os membros do agregado }\end{array}$ & 17 & 63,3 \\
\hline $\begin{array}{l}\text { 3. Capacidade para pagar sem atraso as rendas, as prestações } \\
\text { de crédito e as despesas correntes da residência principal, e } \\
\text { outras despesas não relacionadas com a residência principal }\end{array}$ & 74 & 8,7 \\
\hline $\begin{array}{l}\text { 4. Capacidade para fazer uma refeição de carne ou de peixe, } \\
\text { pelo menos de dois em dois dias }\end{array}$ & 76 & 4,4 \\
\hline 5. Capacidade para manter a casa adequadamente aquecida & 59 & 28,5 \\
\hline 6. Máquina de lavar roupa $(*)$ & 65 & 2 \\
\hline 7. Televisão a cores $(*)$ & 35 & 0,5 \\
\hline $\begin{array}{l}\text { 8. Telefone fixo, ou pelo menos um membro com telemóvel } \\
(*)\end{array}$ & 22 & 1,3 \\
\hline 9. Automóvel (ligeiro de passageiros ou misto) $\left(^{*}\right)$ & 29 & 10,1 \\
\hline
\end{tabular}

* NeStes CASOS, Só SE CONSIDERA UMA SITUAÇÃo dE PRIVAÇÃo FORÇADA SE A FALTA FOR JUSTIFICADA POR INCAPACIDADE FINANCEIRA.

** FONTE: EC, 2007

*** FONTE: Eurostat, 2011

Adoptando um quadro de referência europeu para aferir se estes itens corporizam, de acordo com a abordagem consensual, o padrão de vida mínimo aceite enquanto tal nesse quadro de referência mais alargado, verifica-se igualmente que apenas quatro itens, os mesmos quatro itens, eram considerados em 2007 como absolutamente necessários por uma maioria da população na UE (Guio et al., 2009). Por outro lado, embora todos os itens fossem considerados pela maioria da população da UE como necessários (absolutamente necessário ou necessário), em quatro casos (itens 2, 7, 8 e 9) essa verificação maioritária como necessários só se verificava em entre 12 a 19 países dos 27.

\section{Considerações finais}

No contexto da reflexão aqui apresentada emerge um quadro teórico e empírico bastante desenvolvido que pode servir de guia à investigação social em Portugal no sentido de aproximar a observação da pobreza da sua definição operacional como situação de recursos insuficientes para obter o padrão de vida mínimo aceite enquanto tal.

Neste quadro teórico e analítico salientam-se os seguintes aspectos: a) a grande heterogeneidade dos seres humanos, expressa em características individuais e circunstâncias externas, implica que existam diferenças substanciais na conversão do rendimento e recursos pessoais em funcionamentos ou em satisfação de necessidades, que necessitam de ser reconhecidas e consideradas na operacionalização das medidas; 
b) quer a medida de recursos insuficientes quer a medida de privação material forçada têm limitações importantes na identificação das situações de pobreza e ambas fornecem informação relevante do ponto de vista da análise e observação da pobreza, o que aconselha à utilização de ambas; c) é possível (e desejável) aproximar a operacionalização do conceito da sua definição operacional mais consensual através da definição de um limiar de recursos que tenha por referência aquilo que é necessário para obter o padrão de vida mínimo aceite como tal; e d) a identificação do padrão de vida mínimo aceite pode (e deve) ser aberta a uma "representação mais democrática de interesses", através da incorporação na definição do padrão das percepções prevalecentes numa sociedade relativamente àquilo que se considera que todos deveriam poder ter e de que ninguém deveria ser privado.

\section{BIBLIOGRAFIA}

BRADSHAW, J. e N. Finch (2003), “Overlaps in Dimensions of Poverty”, Journal of Social Policy, 32 (4), pp. 513-525.

BRADSHAW, J. e E. Mayhew (2011), The measurement of extreme poverty in the European Union, Brussels, European Commission, DG Employment, Social Affairs and Inclusion.

BRUTO DA COSTA, A. (1992), The paradox of poverty: Portugal 1980-1989, PhD Thesis. University of Bath.

BRUTO DA COSTA, A., et al. (1985), A pobreza em Portugal, Lisboa, Cáritas.

BRUTO DA COSTA, A., I. Baptista, P. Perista, e P. Carrilho (2008), Um olhar sobre a pobreza: vulnerabilidade e exclusão social no Portugal contemporâneo, Lisboa, Gradiva.

CHIAPPERO-MARTINETTI, E. e S. Moroni (2007), “An analytical framework for conceptualizing poverty and re-examining the capability approach", The Journal of Socio-Economics, 36, pp. 360-375.

DOYAL, L. e I. Gough (1991), A Theory of Human Need, Londres, Palgrave.

EC - EUROPEAN COMMISSION. (2007), Special Eurobarometer 279: Poverty and Exclusion.

FERREIRA, L. V. (2000), A Pobreza em Portugal na Década de Oitenta, Lisboa, CES.

GOEDEMÉ, T. e S. Rottiers (2011), "Poverty in the Enlarged European Union. A Discussion about Definitions and Reference Groups", Sociology Compass, 5 (1), pp. 77-91.

GOUGH, I. (2002), Lists and Thresholds: Comparing our Theory of Human Need with Nussbaum's Capabilities Approach, Paper presented at the Conference on Promoting Women's Capabilities: Examining Nussbaum's Capabilities Approach, Cambridge.

GUIO, A.-C., A. Fusco e E. Marlier (2009), A European Union Approach to Material Deprivation using EUSILC and Eurobarometer data, IRISS Working Paper Series, 19.

KANGAS, O. e V.-M. Ritakallio (2007), "Relative to what?: Cross-national picture of european poverty measured by regional, national and european standards", European Societies, 9 (2), pp. 119-145. 
LAYTE, R., B. Maitre, B. Nolan e C. T. Whelan (2001), "Persistent and consistent poverty in the 1994 and 1995 waves of the european community household panel survey", Review of Income and Wealth, 47 (4), pp. 427-449.

MACK, J. e S. Lansley (1985), Poor Britain, Londres, George Allen \& Unwin.

MAX-NEEF, M. (1992), “Development and human needs”, in P. Ekins e M. Max-Neef (eds.), Real-Life Economics: Understanding Wealth Creation (pp. 197-213), Londres, Routledge.

NOLAN, B. e C. T. Whelan (1996), Resources, Deprivation and Poverty, Oxford, Clarendon Press.

NUNES, F. (2004), Dinâmica de Pobreza e Eficácia do Sistema de Solidariedade e Segurança Social, Tese de doutoramento, Instituto Superior de Economia e Gestão da Universidade Técnica de Lisboa.

PEREIRA, E. (2010), Pobreza e Ruralidade: Uma análise espacial em Portugal Continental, Tese de doutoramento, Instituto Superior de Economia e Gestão da Universidade Técnica de Lisboa.

PEREIRINHA, J. A. (1988), Inequalities, Household Income Distribution and Development in Portugal, PhD Thesis, Institute of Social Studies.

PERRY, B. (2002), "The mismatch between income measures and direct outcome measures of poverty", Social Policy Journal of New Zealand, 19, pp. 101-127.

ROBEYNS, I. (2005), "The capability Approach: a theoretical survey", Journal of Human Development, pp. 93-117.

RODRIGUES, C. F. (2007), Distribuição do rendimento, desigualdade e pobreza: Portugal nos anos 90, Coimbra, Almedina.

RODRIGUES, C. F. e I. Andrade (2010), Monetary Poverty, Material Deprivation and Consistent Poverty in Portugal, Paper presented at the II Conference in Memory of Maria Leonor Vasconcelos Ferreira, Porto.

ROWNTREE, B. (1902), Poverty: A Study of Town Life (2nd ed.), Londres, Macmillan \& Co.

SEN, A. (1983), “Poor relatively speaking”, Oxford Economic Papers, 35, pp. 153-169.

SEN, A. (1985), “A Sociological Aproach to the Measurement of Poverty: a Reply to Professor Peter Townsend", Oxford Economic Papers, 37, pp. 669-676.

SEN, A. (1992), Inequality Reexamined, Oxford, Clarendon Press.

SEN, A. (1999 [1981]), Pobreza e Fomes: um ensaio sobre direitos e privações (Freitas e Silva, Trad.), Lisboa, Terramar.

SEN, A. (2000 [1999]), Desenvolvimento como liberdade (L. Motta, Trad.), São Paulo, Companhia das Letras.

TOWNSEND, P. (1979), Poverty in the United Kingdom: a survey of households and standards of living, Harmondsworth, Penguin Books.

WHELAN, C. T. e B. Maître (2009), “The 'europeanisation' of reference groups: a reconsideration using EU-SILC", European societies, 11 (2), pp. 283-309.

\section{NOTAS}

1. Esta expressão é utilizada por Doyal e Gough (1991) no contexto da teoria das necessidades humanas. 
2. Esta leitura retoma em parte a reflexão realizada sobre este assunto na tese de doutoramento da autora, orientada pelo Professor Doutor José António Pereirinha.

3. Note-se que esta correspondência só é possível se a pobreza for identificada com uma situação de recursos económicos insuficientes. Neste caso, a capacidade relevante para determinar a situação de pobreza é a capacidade material, que depende do rendimento (num sentido lato).

4. Pelo contrário, alguns autores consideram que todo o processo associado ao desenvolvimento da medida monetária relativa ao nível europeu "é destituído de fundamentação científica" (Bruto da Costa et al., 2008: 98).

5. A medida de privação material adoptada ao nível europeu inclui 9 indicadores (ver Gráfico 2). Consideram-se em situação de privação material os indivíduos residentes em agregados em que se verifica a privação forçada em três ou mais destes indicadores.

6. Isto não significa que o exercício de identificação dos pobres é um exercício subjectivo ou prescritivo: "Descrever uma prescrição prevalecente é um acto de descrição, e não de prescrição. (...) Para a pessoa que está a estudar e a medir a pobreza, as convenções da sociedade são questões de facto (quais são os padrões contemporâneos?), e não questões de moralidade ou pesquisa subjectiva (quais deviam ser os padrões contemporâneos? Quais deviam ser os meus valores? O que é que sinto em relação a isto tudo?)" (Sen, 1999 [1981]: 35).

7. Embora o critério dominante de selecção de indicadores nesta abordagem seja o de reconhecimento do item como necessário pela maioria da população, através da aplicação de um inquérito de opinião, o procedimento prosseguido por Mack e Lansley (1985) envolve igualmente uma combinação de julgamento do investigador e de referências científicas na selecção inicial dos itens.

8. Este Eurobarómetro apresenta a opinião dos inquiridos sobre o grau de necessidade de uma série de 53 itens para a obtenção de um padrão de vida decente ou aceitável no país respectivo de residência, com cinco opções de resposta: "Absolutamente necessário, ninguém deveria ser privado”, “Necessário", "Desejável mas não necessário”, "Nada necessário" e "Não sabe”. Os 53 itens estão organizados em cinco áreas: meios financeiros, condições da habitação, bens duráveis, necessidades básicas e integração social.

9. Os resultados deste Eurobarómetro têm sido também utilizados em alguns estudos para determinar os pesos de cada um dos 9 indicadores seleccionados ao nível da UE numa medida ponderada de privação material (e.?g., Guio et al., 2009; Rodrigues e Andrade, 2010).

10. A formulação dos itens no Eurobarómetro é, em vários casos, diferente da formulação dos itens utilizados na medida de privação material, pelo que a equivalência não é perfeita.

\section{RESUMOS}

O desenvolvimento de uma medida objectiva, consensual, adequada para a observação da pobreza em Portugal, apoiada em investigação científica, e que permita determinar o rendimento necessário para obter o nível de vida mínimo aceitável no nosso país é um desafio importante que se coloca à investigação social nesta área. 0 principal objectivo deste artigo é o de realizar uma leitura crítica das principais abordagens à operacionalização do conceito de pobreza, apoiada em resultados de investigação recente. Nesta leitura crítica é apresentado um quadro teórico e empírico que pode "guiar" a investigação social na resposta ao desafio colocado. 
The development of an objective and consensual measure to study poverty in Portugal, supported by scientific research, and enabling the estimation of the income required to obtain the minimum acceptable standard of living in our country is a major challenge facing social research in this area. The main aim of this paper is to present a critical reading, based on results of recent research, of the main approaches to operationalize the concept of poverty. In this critical reading, a theoretical and empirical framework that could guide social research in responding to that challenge is presented.

\section{ÍNDICE}

Keywords: poverty, deprivation, concepts, measurement, Portugal

Palavras-chave: pobreza, privação, conceitos, medição, Portugal

\section{AUTOR}

\section{ELVIRA SOFIA LEITE DE FREITAS PEREIRA}

Centro de Administração e Políticas Públicas, Instituto Superior de Ciências Sociais e Políticas, Universidade Técnica de Lisboa, epereira@iscsp.utl.pt 